\title{
The role of spontaneous construction for post-disaster housing
}

\author{
D. Félix \& A. Feio \\ University Lusíada, CITAD, Vila Nova Famalicão, Portugal
}

J. M. Branco

University of Minho, ISISE, Guimarães, Portugal

José S. Machado

LNEC, Portugal

\begin{abstract}
Housing is crucial for living and well-being. Due to its vulnerability, one of the most severe consequences after natural disasters has been the destruction of houses, causing impressive numbers of homeless people.

After those situations, it is imperative to start the reconstruction works and the provision of houses is a crucial task, since they can help to restore the livelihoods of the affected people. The urgency to supply housing quickly, has lead the formal construction sector to neglect user's needs and expectations, and consequently has not conducted to successful solutions. Contrary to that, informal housing solutions have reached successful results in addressing the user's cultural needs and expectations. Some studies have presented the advantages of spontaneous construction solutions, yet they seem to be ignored and contradicted by the formal construction sector. This study aims to present an assessment of the potentials of spontaneous construction solutions for post-disaster housing development.
\end{abstract}

\section{INTRODUCTION}

Natural disasters have drastically increased during the last decades being one of the most important causes of damage on the built environment. A great amount of buildings have suffered severe damages, sometimes collapsed entirely. Housing buildings are extremely vulnerable to natural disasters and the number of destroyed or greatly damaged houses is often dramatic. In crisis scenarios like those, the number of homeless people can reach impressive numbers. In the same way, most of the basic services, utilities and infrastructures may suffer serious damages as well. Living under those extreme conditions is difficult and in order to restore the natural balance of the affected communities, it is essential to start the reconstruction works as soon as possible. Post-disaster housing is an important issue of reconstruction processes, since a house is a crucial element to live with a consistent level of comfort, which is fundamental in a chaotic and complex post-disaster situation. The sooner the victims are provided with a house, the sooner they have the basic conditions to return to their normal life activities.

The urgent need for housing solutions has lead to numerous debates and discussions. A lot of solutions and strategies have been developed, yet some problems seem to persist. Dealing with pressure, lack of resources, problems of coordination among the actors involved, and other difficulties, make construction activities in post-disaster areas extremely arduous. The urgency for housing supplying under these circumstances has resulted in wrong choices and decisions and the adopted solutions have been criticized for being unsustainable and culturally inadequate (ElMasri \& Kellett, 2001; Dikmen et al., 2012). Despite the great amount of studies and reports that have presented the common problems and also suggested some feasible alternatives, most of the formal post-disaster housing processes seem to follow the same principles and options, which result in the same problems. On the contrary, some studies have shown that spontaneous 
housing solutions seem to have reached successful solutions in terms of users' satisfaction (ElMasri \& Kellett, 2001; Lizarralde \& Davidson, 2006).

This study intends to validate that some strategies and solutions adopted by the informal sector can provide important knowledge to help overcoming the common problems of the formal post-disaster housing strategies. Through the literature review on the topic, and exploring concepts such as local resources utilization, community participation, and indigenous knowledge, the paper aspire to demonstrate that solutions from the informal sector can play an important role on the development of post-disaster housing solutions.

\section{THE IMPORTANCE OF POST-DISASTER HOUSING}

Housing is one of the most important needs for people and it is also essential for their wellbeing. More than a physical structure or an object, a house represents a home, which is the space that provides the conditions for family life, comfort, protection, and privacy. Covering the social, spiritual and psychological needs, a house is the space for people to live in and to live with dignity. It provides a sense of belonging, social integration, security, and cultural identity. People gain part of their identity through their home and, in turn, a home reflects aspects of its users (Kellett \& Tipple, 2000).

More than a physical deprivation, losing a home means losing dignity, identity and privacy (Barakat, 2003). Post-disaster housing is essential to re-establish the life of the affected community during a difficult and problematic situation after a disaster. It is a fundamental step to establish some sense of normalcy in the victims' life, replacing uncertainty by safety (Bedoya, 2004). Post-disaster housing also prevents the increase of deaths and the spread of disease because it supplies conditions for personal hygiene and gives protection against external factors.

The issues discussed above show that housing is a complex issue that reflects cultural, traditional, and economical questions. During a demanding post-disaster reconstruction process, the complexity rises because people are psychologically affected and working under extreme pressure, the available resources are scarce, and time is short to develop housing solutions. In the same way, the wide range of available solutions and some confusion and inconsistency about the terms used, mainly between shelter and housing (Quarantelli, 1995), creates several obstacles to find effective housing solutions.

\section{DIFFERENT APPROACHES FOR POST-DISASTER HOUSING}

There are two main approaches for housing provision after disasters: (1) the formal construction sector or top-down approach, and (2) the informal construction sector or bottom-up approach (El-Masri \& Kellett, 2001; Keivani \& Werna, 2001; Lizarralde \& Davidson, 2006; Dikmen et al., 2012). While the formal sector is conducted by governments, non-governmental organizations (NGOs) or other recognized institutions, the informal sector is based on solutions that involve the user. The main differences between them are the methods and resources used. The formal sector uses mainly industrialized materials and ways of production, building standards, and also specialized workforce. Contrary to that, the informal sector is characterized for its spontaneous construction through local workforce, often using indigenous and traditional materials and construction techniques (Keivani \& Werna, 2001). The constructions from the informal sector can be considered non-engineered buildings. According to Boen \& Pribadi (2007), nonengineered buildings are constructed spontaneously in the traditional manner and without intervention from architects or engineers. The authors also state that these buildings can be divided into two main categories: (1) buildings that use locally available materials and follow local tradition and culture, commonly called indigenous or vernacular buildings; and (2) buildings that do not adopt traditional craftsmanship and materials.

The formal sector has been greatly criticized due to the unsuccessful solutions implemented, mainly due to problems of low sustainability and cultural inadequacy. On the other hand, the informal sector seems to have been capable of housing most of the poor residents in developing countries with solutions that fit their lifestyles and needs (Vikram \& Rybczynski, 1999; Lizarralde \& Davidson, 2006). 


\section{DIFFERENCES BETWEEN FORMAL AND INFORMAL SECTORS}

The need to quickly and economically re-settle those who lost their homes, has led the formal sector to emphasize in standardized, mass-produced and technology-oriented solutions (ElMasri \& Kellett, 2001; Johnson, 2007, Lizarralde \& Davidson, 2006; Lizarralde \& Root, 2007). However, that urgency has not conducted to effective results. About thirty years ago, the guidelines from the Office of the United Nations Disaster Relief Co-Ordinator - UNDRO (1982) stated that specifications for shelter can only be given in a precise local context. In the same way, it affirmed that standardization oversimplifies the problem and that the concept of a universal or standard shelter is not feasible because it ignores crucial factors, such as cultural values and climatic variations. Practically twenty years later, El-Masri and Kellett (2001) defended that top-down approaches failures are due to standardization and technologically oriented solutions. In the same way, Barakat (2003) asserted that imported solutions impose designs that may be culturally aliens. Recently, Dikmen et al. (2012) insisted on the fact that top-down approaches neglect cultural conditions and users' needs. This shows that during the last three decades the same problems have happened due to the same mistakes and misunderstandings appointed by UNDRO (1982) three decades ago.

It seems that there is a strongly technocratic bias in reconstruction programs, focusing on houses that are safe built but without certainty that such solutions are affordable and culturally acceptable (Twigg, 2006). Indeed, those solutions are frequently a result of what a restrained group of professionals consider the most appropriate and not what is suitable for local inhabitants (Lizarralde \& Davidson, 2006). Thus, solutions of such approaches often result in expensive and alien housing units that fail to address users' needs and expectations (El-Masri \& Kellett, 2001; Gulahane \& Gokhale, 2012; Dikmen et al., 2012). These solutions tend to be expensive because (a) they need to be transported to the site, and transportation can be two thirds of the cost of materials (Harris, 2011), (b) the local community most of the times do not have the appropriate skills to handle with the new materials and techniques, and so there is a need to hire external and specialized workforce; and (c) the maintenance is extremely expensive because the users need to invest in imported materials and skilled workforce to upkeep their houses. Thus, this is an unsustainable approach both in the short-term, during the height of the disaster, and in the long-term, over the time. Furthermore, this approach does not improve the local economy, since there is no investment in local companies and local resources.

Due to the inappropriateness of the solutions, users often try to make modifications to fit their lifestyle and needs. Since local users do not have the appropriate knowledge or skills to handle with the new construction systems and materials, most of the times those changes make units more vulnerable to future disasters, see fig. 1. Likewise, users cannot do the maintenance of the houses because it is expensive and require specialized skills, which also increase the vulnerability of the solutions over the time. In the same way, inadequate solutions frequently result in the abandonment of the houses supplied (El-Masri \& Kellett, 2001; Harris, 2011; Dikmen et al., 2012), as, for example, in the case of Indonesia after the 1992 Earthquake (Boen \& Jigyasu, 2005), and in Marathwada following the 1993 earthquake (Salazar, 2002). Sometimes the houses lie empty because people refuse to move to them, as it happened in Turkey following the earthquake of 2000 (Dikmen, 2006), and in Gujarat, India, after the earthquake of 2001 (Barenstein, 2006).
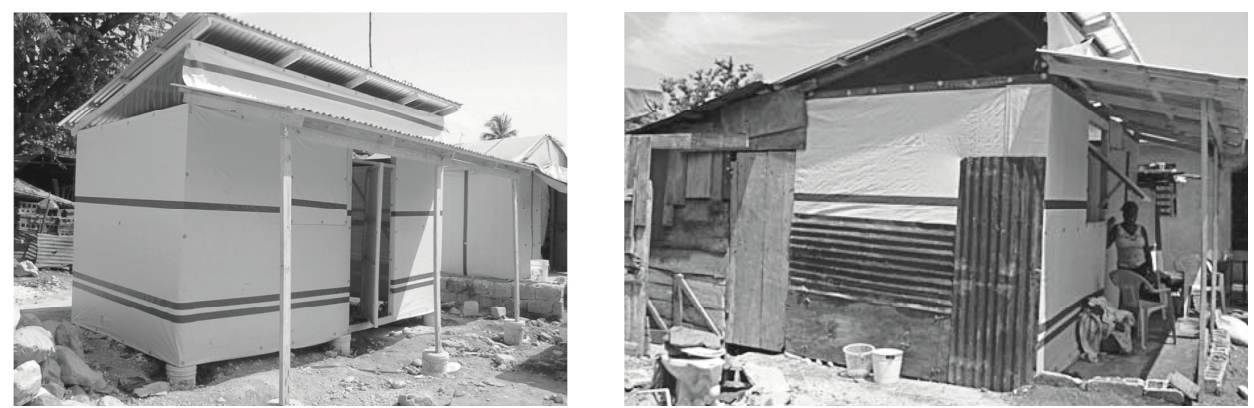

Figure 1.Housing unit before being used and after the user modifies it. The modifications increased the vulnerability of the construction. (http://openarchitecturenetwork.org). 
On the other hand, the informal sector is characterized for involving the user, adopting appropriate technologies for local people and using local resources (El-Masri \& Kellett, 2001). Indeed, the inhabitants of the informal settlements are commonly resourceful and innovative in conceiving housing solutions that are affordable and can be quickly built (Gottsmann \& Osman, 2012). This is possible because those approaches emphasize variety, slow evolution and smooth implementation. Through the use of local resources, informal solutions seem to be more economic and better tailored to the needs, aspirations, and also abilities of the users (El-Masri \& Kellett, 2001). Furthermore, involving the community and using local resources can give a potential contribute to reinforce the sense of place attachment, which is crucial to improve the reconstruction process.

A study developed by Lizarralde and Davidson (2006) found various common patterns in spontaneous housing solutions, confirming that despite the fact that there is no equal final units, a number of restraining process variables exists in the informal housing process. However, this knowledge is not considered by the formal construction sector (Johnson, Lizarralde \& Davidson, 2005), and is frequently ignored and contradicted, see tab. 1. One of the main differences between those opposite approaches found in their study was the strategies used to reduce costs and increase affordability. While the formal sector emphasizes uniformity in forms, sizes, materials and technologies, the informal sector takes advantage of recycling, progressive construction, and variety of solutions sizes and forms. In the same way, their study shows that button-up solutions are characterized by the flexible use of indoor and outdoor spaces, and also accommodate a variety of functions and uses, mixing housing with working activities. This concept of mixed-used is undoubtedly important, since in the informal solutions housing is often not for home life alone. A house can be a production place, a market place or an entertainment centre, etc. (Kellett \& Tipple, 2000). In ignoring these principles and priorities, the standardized designs of top-down solutions do not provide integration between indoor and outdoor spaces, being extremely rigid to allow modifications. Formal solutions creates what Lizarralde and Davidson (2006) call the "box effect", solutions which do not provide spaces to allow housing expansions, income-generation activities, and socializing areas.

Table 1. Differences between informal housing and post-disaster formal projects according to Lizarralde and Davidson (2006).

\begin{tabular}{|c|c|c|}
\hline & Informal housing & Post-disaster formal projects \\
\hline \multirow{3}{*}{$\begin{array}{l}\text { Housing } \\
\text { form }\end{array}$} & Flexible use of interior and exterior spaces. & Rigid division between indoor and outdoor. \\
\hline & Combination of one to three storeys. & Only one storey. \\
\hline & $\begin{array}{l}\text { Emphasis on quality and comfort of interior } \\
\text { spaces with little interior subdivisions. }\end{array}$ & Clear subdivisions of spaces. \\
\hline \multirow[b]{2}{*}{$\begin{array}{l}\text { Housing } \\
\text { evolution }\end{array}$} & $\begin{array}{l}\text { Ambiguous distinction between original unit } \\
\text { and later additions or modifications. }\end{array}$ & $\begin{array}{l}\text { Inadequate integration between original unit } \\
\text { and later additions or modifications. }\end{array}$ \\
\hline & $\begin{array}{l}\text { Imperceptible distinction between temporary } \\
\text { units and permanent houses. Progressive } \\
\text { building without clear conclusion. }\end{array}$ & $\begin{array}{l}\text { Clear distinction between temporary and } \\
\text { permanent homes units. Project with clear } \\
\text { conclusion. }\end{array}$ \\
\hline \multirow{2}{*}{$\begin{array}{l}\text { Aesthetic } \\
\text { principles }\end{array}$} & $\begin{array}{l}\text { Façade without uniformity; diversity of tex- } \\
\text { tures and colors. }\end{array}$ & $\begin{array}{l}\text { Preoccupation with regularity of the façade } \\
\text { finishes and colors. }\end{array}$ \\
\hline & Abundant diversity between units. & Homogeneity and standardization of units. \\
\hline \multirow{2}{*}{$\begin{array}{l}\text { Use of } \\
\text { materials }\end{array}$} & Recycled materials and components. & Low use of recycled materials. \\
\hline & Different materials and techniques. & Homogeneity of materials and technologies. \\
\hline \multirow{2}{*}{$\begin{array}{l}\text { Functio- } \\
\text { nality }\end{array}$} & Diversity of functions and uses. & Differentiation of uses. \\
\hline & $\begin{array}{l}\text { Importance of protection from thefts and as- } \\
\text { saults. Emphasis on fencing the land. }\end{array}$ & $\begin{array}{l}\text { Mainly concerned with structural safety. } \\
\text { Fencing the land is not a priority. }\end{array}$ \\
\hline \multirow{3}{*}{$\begin{array}{l}\text { Settlement } \\
\text { layout }\end{array}$} & Diversity of open spaces. & Regularity of open spaces. \\
\hline & Hierarchy of streets and paths. & Homogeneity in streets and paths. \\
\hline & Diversity of plot sizes and forms. & Uniformity of plot sizes and forms. \\
\hline
\end{tabular}




\section{ADVANTAGES AND LIMITATIONS OF THE INFORMAL SECTOR SOLUTIONS}

The user's satisfaction is one of the most important factors to reach successful post-disaster housing solutions and it is closely related to the users' participation (Lizarralde \& Bouraoui, 2012). The spontaneous solutions are developed by users' themselves at their own pace and according to their own priorities, expectations and requirements. This way, most of these housing solutions are characterized for a great level of satisfaction.

The use of local knowledge and resources is greatly valuable in terms of livelihoods because it uses local community skills and labor (Twigg, 2006). The active participation of the disasteraffected community can be a useful way to restore the sense of pride and neighborhood relationship for people who have been through a trauma (Barakat, 2003). Moreover, and according to some authors (Shaw et al., 2009; Boen \& Pribadi, 2007), indigenous and traditional construction knowledge has been developed and adopted to local environment over the time, being tested by local phenomena and influenced by local conditions, such as climate and culture. Thus, some indigenous building technologies can be more resistant to disasters when compared to some modern building methods (Twigg, 2006; Shaw et al., 2009; Boen \& Pribadi, 2007; Makhanu et al., 2006; Gulahane \& Gokhale, 2012).

Carefully formulated, the use of local knowledge allows for the development of safe structures that can be built through techniques adapted to the local knowledge. Using local workforce, local materials, and considering the cultural integration, it is possible to develop solutions that fit users' needs and simultaneously are structurally safe, see fig.2.
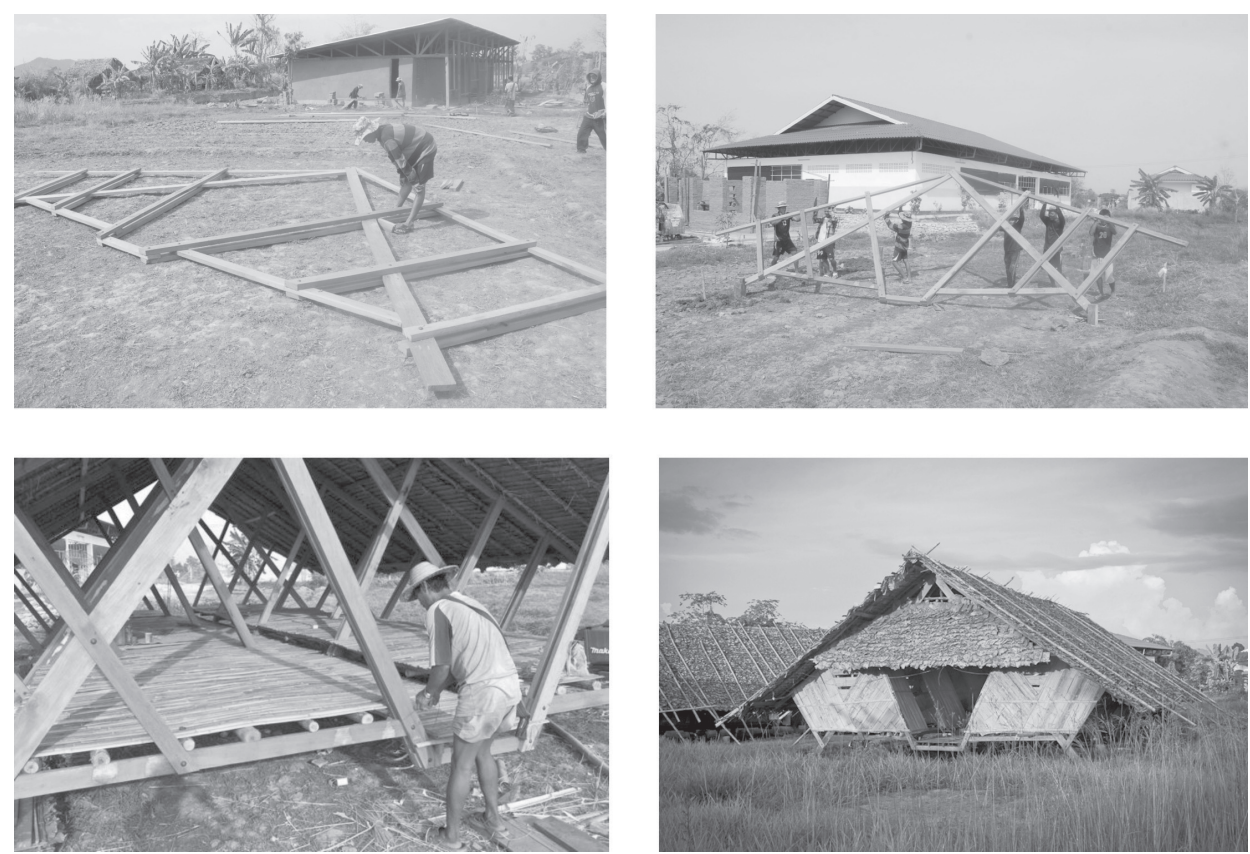

Figure 2. A simple and safe structure built with materials locally available and erected only with manpower through traditional construction. The assembly and maintenance is easy because the construction techniques and materials are well known for users (www.openarchitecturenetwork.org).

However, the informal construction has also limitations that must be considered. As it was discussed behind in this study, there are two types of spontaneous construction, and most of the advantages belong to the first category. The second one, which is not based in traditional and indigenous knowledge, frequently does not follow safe construction requirements and uses poor workmanship and low quality materials (Boen \& Pribadi, 2007). Due to the lack of structural safety control, this kind of spontaneous construction have had very poor performance during past disasters and resulted in many deaths and damages throughout the world. So, not all spontaneous solutions can be considered as acceptable models to follow.

In the same way, studies have found negatives outcomes in some community-based approaches (Lizarralde \& Massyn, 2008). Thus, not all kinds of community or users involvement 
are synonym of favorable outcomes and their participation has to be locally and carefully decided according to their abilities and skills (Davidson et al., 2007).

Finally, in cases of large scale destruction, the mass consumption of local resources can lead to lack or sudden disruptions of local material supply and also severe environmental impacts such as deforestation (Shelter Centre, 2012).

\section{BENEFITS FROM THE FORMAL SECTOR}

The fact that most of the formal post-disaster housing solutions have suffered the problems discussed in this study does not mean that their know-how should not be used. Modern ways of construction and new materials are undoubtedly powerful resources to improve solutions for disaster situations. The problem lies on the way these resources have been used rather than on the resources themselves. If properly introduced and culturally integrated, new construction systems and materials may considerably improve the safety and quality of post-disaster housing solutions. According to Shaw (2009), housing provides a great opportunity to integrate indigenous and modern technologies. The use of prefabrication is an example that some authors (Lizarralde \& Root, 2007; Davidson, Lizarralde \& Johnson, 2008; Garofalo \& Hill, 2008) have considered as valuable.

It seems that a hybrid approach may be a feasible alternative to develop solutions that are culturally and locally adequate and simultaneously take advantage from modern construction systems. The Paper Log Houses developed by Shigeru Ban are a great example of this combination. The first solution developed to be used after the Kobe earthquake in 1995 was adapted to the Indian context after the Gujarat earthquake in 2001. The units used the mass-produced and prefabricated paper tube structure from the original solution, but it was used a traditional mud floor and a locally woven cane mat was used for the roof. Thus, the solution is a balanced combination of industrialized and local construction systems, see fig. 3 .
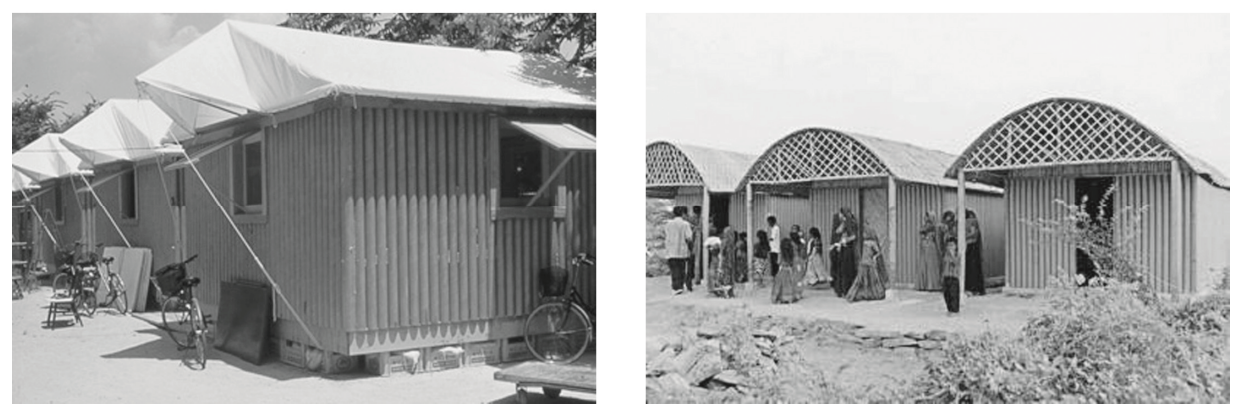

Figure 3. Paper Log Houses: (left) solution used in Japan and (right) the solution used in India (http://www.shigerubanarchitects.com//).

\section{RECOMMENDATIONS FOR SUSTAINABLE AND SATISFACTORY SOLUTIONS}

The issues previously discussed seem to open space to propose some recommendations that can be key drivers to improve cultural adequacy, sustainability, and structural safety of post-disaster housing solutions. These recommendations are presented below:

- Local context understanding: Most importantly, precise specifications for post-disaster housing can only be given in a precise local context (UNDRO, 1982). It is essential to have a complete knowledge about the context, their inhabitants and culture, local resources available, natural and climacteric conditions, etc., in order to develop culturally and locally sensitive housing solutions;

- Hybrid and systemic approach: A well balanced approach that takes as much advantage as possible from the local resources and at the same time introduces new technologies where appropriate, allows for more sustainable and better tailored solutions. Since housing is a complex issue, a systemic approach is crucial to make sure that all cultural, socioeconomical, environmental, structural safety, etc., issues are considered; 
- Community participation: Although not all kinds of participation can bring positive outcomes, involving the community in the assessment of their needs and expectations is crucial to guarantee their satisfaction;

- Local materials and construction systems: The use of local techniques and materials contributes to reduce the costs of construction and maintenance, and also improves the local economy;

- Simple construction systems: The construction systems should be as simple as possible. The use of structures and systems based on light and small elements allow faster and simpler construction because they are easy to transport, handle and assembly;

- Flexible solutions: Flexibility is a crucial factor for post-disaster housing (UNDRO, 1982; Kellett \& Tipple, 2000; El-Masri \& Kellett, 2001; Barakat, 2003; Bedoya, 2004; Lizarralde $\&$ Davidson, 2006). Flexible spaces are easily personalized and modified according to users' needs and resources. The patterns established by Lizarralde \& Davidson (2006) can be a useful knowledge to consider during the development of the solutions.

- Houses and surroundings as a whole: The outdoor spaces next to the houses and the other spaces around are extremely important and they should be planned with the same accuracy.

\section{CONCLUSIONS}

This study found that the some problems seem to persist in formal post-disaster housing processes. Most of those problems are due to the way the solutions are developed rather than the technical-solutions themselves. Formal projects frequently neglect cultural and local conditions, providing solutions that are technically efficient but which do not match the lifestyles and needs of the users. Contrary to that, spontaneous solutions seem to have been successful in providing affordable and culturally appropriate solutions.

The research does not suggest that post-disaster housing processes should replicate the spontaneous solutions. It proposes that some spontaneous construction strategies can be helpful to overcome some problems, mainly the ones concerned with cultural inadequacy and sustainability. A well balanced solution that takes advantage of both spontaneous and formal construction, through a sensitive approach to local conditions that focus more on people than on physical aspects of the houses, is the key to produce more successful post-disaster housing solutions. This study tried to demonstrate how helpful the knowledge from spontaneous construction can be.

\section{ACKNOWLEDGEMENT}

The first author gratefully acknowledges the financial support of Fundação para a Ciência e a Tecnologia, FCT, through grant SFRH / BD / 73853 / 2010.

\section{REFERENCES}

Barakat, S. (2003). Housing Reconstruction after conflict and disaster. London: Overseas Development Institute.

Barenstein, J. D. (2006). Housing reconstruction in post-earthquake Gujarat: a comparative analysis. Overseas development institute (ODI). Humanitarian practice network (HPN).

Bedoya, F. G. (2004). Hábitat transitorio y vivienda para emergencias. Tabula Rasa. , 145-166.

Boen, T., \& Jigyasu, R. (2005). Cultural considerations for post disaster reconstruction post-tsunami challenges. In UNDP Conference. Available at: http://www.adpc.net/IRC06/2005/4-6/TBindo1.pdf

Boen, Teddy, \& Pribadi, K. S. (2007). Engineering the non-engineered houses for better earthquake resistance in Indonesia. Proceedings of the DRH Contents Meeting-EDMNIED, Kobe, Japan, Available at: http://drh.edm.bosai.go.jp/files/6cc5597e09050a9b482d9f257c5f256ec28f6e50/7_PT8_P.pdf

Davidson, C. H., Johnson, C., Lizarralde, G., Dikmena, N., \& Sliwinskia, A. (2007). Truths and myths about community participation in post-disaster housing projects. Habitat International , 100-115.

Davidson, C., Lizarralde, G., \& Johnson, C. (2008). Myths and Realities of Prefabrication for PostDisaster Reconstruction. 4th International i-Rec Conference 2008 - Building resilience: achieving effective post-disaster reconstruction. Christchurch, New Zealand. 
Dikmen, N., Elias-Ozkan, S. T., \& Davidson, C. (2012). Comparison of post-disaster housing procurement methods in rural areas of Turkey. Open House International, 37, 28-39.

El-Masri, S., \& Kellett, P. (2001). Post-war reconstruction. Participatory approaches to rebuilding the damaged villages of Leabanon: a case study of al-Burjain. Habitat International , 25, 535-557.

Garofalo, L., \& Hill, D. (2008). Prefabricated Recovery: Post-Disaster Housing Component Production and Delivery. Without a Hitch - New Directions in Prefabricated Architecture, (pp. 64 - 71). Massachusetts.

Gottsmann, D., \& Osman, A. (2012). Environments of change: an open building approach towards a design solution for an informal settlement in Mamelodi, South Africa. Open House International, 37, 7182.

Gulahane, K., \& Gokhale, V. A. (2012). Design Criteria for Temporary Shelters for Disaster Mitigation in India. In Lizarralde, G., Jigyasu, R., Vasavada, R., Havelka, S., Duyne Barenstein, J. (eds.). Participatory design and appropriate technology for disaster reconstruction. Conference proceedings. 2010 international i-Rec conference. Ahmedabad, India. Montreal: Groupe de recherche IF, GRIF, Université de Montréal. Available at: www.grif.umontreal.ca/pages/conferenceiREC2010.htm.

Harris, V. L. (2011). The architecture of risk. In M. J. Aquilino, Beyond Shelter. Architecture for Crisis (pp. 12-23). London: Thames \& Hudson.

Johnson, Cassidy, Gonzalo Lizarralde and Colin Davidson (2005). Reconstruction in developing countries: A case of meta procurement. CIB Proceedings W92, T23, W107 Conference in 2005. Las Vegas: CIB.

Johnson, C. (2007). Impacts of prefabricated temporary housing after disasters: 1999 earthquakes in Turkey. Habitat International 31, 36-52.

Keivani, R., \& Werna, E. (2001). Refocusing the housing debate in developing countries from a pluralist perspective. Habitat International, 25, 191-208.

Kellett, P., \& Tipple, A. G. (2000). The home as workplace: a study of income-generating activities within the domestic setting. Environment \& Urbanization, 12, 203-214.

Lizarralde, G., \& Davidson, C. (2006). Learning from the poor. In i-Rec conference proceedings 2006: Post-disaster reconstruction: Meeting the stakeholders' interest. Florence: i-Rec.

Lizarralde, G., \& Root, D. (2007). Ready-made shacks: Learning from the informal sector to meet housing needs in South Africa. In Proceedings of the CIB congress, Cape Town, South Africa.

Lizarralde, G. and Massyn, M. (2008). Unexpected negative outcomes of community participation in lowcost housing projects in South Africa, Habitat International 32, 1-14.

Lizarralde, G. \& Bouraoui, D. (2012). User's participation and satisfaction in post-disaster reconstruction. In Lizarralde, G., Jigyasu, R., Vasavada, R., Havelka, S., Duyne Barenstein, J. (eds.). Participatory design and appropriate technology for disaster reconstruction. Conference proceedings. 2010 international i-Rec conference. Ahmedabad, India. Montreal: Groupe de recherche IF, GRIF, Université de Montréal. Available at: http://www.grif.umontreal.ca/pages/conferenceiREC2010.htm.

Makhanu, S.K.; Oteng'i, S.B.B.; S.S. China, S.S.; Waswa, G. W.; Masibo, M.N.; Masinde, G.W.B. (2006). Indigenous construction technologies in flood-prone areas of Western Kenya. In i-Rec conference proceedings 2006: Post-disaster reconstruction: Meeting the stakeholders' interest. Florence: iRec.

Quarantelli, E. L. (1995). Patterns of sheltering and housing in US disasters. Disaster Prevention and management , 4, 43-53.

Salazar, A. (2002). The crisis of modernity of housing disasters in the developing countries: participatory housing and technology after the Marathwada (1993) earthquake, International Conference on PostDisaster Reconstruction: Improving Post-Disaster Reconstruction in Developing Countries, 23-25 April, Montreal: i-Rec. Available at: http:/www.grif.umontreal.ca/pages/i-rec\%20papers/alex.PDF

Shaw, R., Takeuchi, Y., Uy, N., \& Sharma, A. (2008). Indigenous Knowledge, Disaster Risk Reduction.

Shelter Centre (2012). Transitional shelter guidelines. Available at: www.sheltercentre.org/library

Twigg, J. (2006). Technology, Post-Disaster Housing Reconstruction And Livelihood Security. (B. H. Centre, Ed.) Disaster Studies Working Paper No.15.

UNDRO. (1982). Shelter after Disaster: Guidelines for Assistance. New York: United Nations.

Vikram, B., \& Rybczynski, W. (1999). How the other half builds. In N. T. Dines, \& K. D. Brown, Timesaver standards: Site construction details manual. Montreal: McGraw-Hill. 